\title{
Enhancing Evidence-Based Coaching Practice by Developing a Coaching Relationship Competency Framework
}

\author{
Yi-Ling Lai \& Almuth McDowall
}

\begin{abstract}
This chapter takes a competence focused approach to coaching in order to outline relevant knowledge, skills and abilities (KSAs) for Coaching Psychologist to enhance coaching relationship towards positive outcomes. We commence with a comparison of relevant existing competency frameworks for coaching practitioners, such as the International Coach Federation (ICF), Association for Coaching (AC) and also the Special Group in Coaching Psychology (BPS, UK) to determine their similarities and differences. Our analysis outlines how the different models feature in terms of their development process, conceptual robustness and also how they address cross cultural issues in coaching. As a next step, we outline a rigorous role analysis to develop a comprehensive Coaching Relationship Competency Framework (CRCF) focusing furthering the effectiveness of the coaching relationship. A Systematic Review which can inform us about current knowledge as well as gaps and research trends in the field therein is essential prior primary research. The review results determined the need to focus on the coaching relationship and in particular the coach's competencies for facilitating this in an effective way. It then fed into three subsequent studies to draw up a new competence framework, which has been tested out through a pilot study. A Coaching Relationship Competency Framework with 75 behavioural indicated was identified and provided a guideline for future practice and research by spelling out (a) 'Soft Skills' which are key behaviours needed in any coaching relationship such as
\end{abstract}


"listening actively", and (b) 'Hard Skills', such as "establishing mutually agreed goals", which can inform concrete coach training and development. In short, we argue that a behavioural focus and framework has much to offer by providing benchmarks for training and reflective practice. We illustrate the chapter with brief interactive exercises and reflections for practice, giving attention to cross cultures issues as appropriate. In conclusion, the key contribution of the framework presented here is that it was designed from the outset to acknowledge the perspectives of coaches, coachees and also commissioning clients.

\section{Key words: evidence-based coaching, competency framework, coaching}

Lai, Y. M. \& McDowall, A. (2016) Enhancing evidence-based coaching practice by developing a coaching relationship competency framework. In Van Zyl, L.; Odendaal A. and Stander M. (Eds) Coaching Psychology: Meta-theoretical perspectives and applications in Multi-cultural Contexts. Springer. 


\section{Introduction}

The role of the coaching relationship in facilitating coaching outcomes has been widely discussed and investigated since 2008 (Baron \& Morin, 2009; Boyc et al., 2010; de Haan, 2008; Palmer \& McDowall, 2010; de Haan et al., 2013). However, most of the existing studies are still not adequate to confirm what the active factors are for an effective coaching relationship and how these factors could be optimised in the coaching process. This chapter presents a different approach to understand the coaching relationship by investigating essential coach's attributes and competencies facilitating an effective coaching relationship. It commences with a brief discussion on contemporary issues and challenges in the field of coaching. The diversity of coaching disciplines has shifted the research focus from examining singular coaching intervention to studying the effectiveness of coaching process. The association between the coaching relationship and coaching outcomes has been examined through several studies (Baron \& Morin, 2009; Boyce et al., 2010; de Haan et al., 2013), nevertheless there is no denying that more rigorous evidence is required to examine common factors for a better desired working relationship in the coaching process. A systematic review on coaching psychology was carried out to ascertain specific research topics according to existing issues in coaching filed before further any primary studies. The review results (Lai \& McDowall, 2014) indicated a comprehensive role analysis study to identify and validate required competencies for coaches to establish a productive coaching relationship is necessary. The detailed investigation process and results of this coaching relationship competency framework study will be summarised in this chapter. 


\section{Contemporary Issues in Coaching and Coaching Psychology}

Given the increase in coaching application in the organisational and leadership development field, the evaluation of the impact of coaching on personal and organisational development is a key interest to organisational stakeholders and coaching practitioners (Passmore \& Fillery-Travis, 2011). Whilst the ultimate objective of coaching is similar to other helping interventions to facilitate positive life and behavioural change, organisations (and coaches) need to demonstrate that coaching produces positive outcomes and is worth continued investment. Thus, the promotion of evidence-based coaching to document any effects on concrete personal development or organisational-based (e.g. ROI) outcomes is essential in contemporary coaching study (Passmore \& Fillery-Travis, 2011).

However, some issues emerged in the development of evidence-based coaching due to the diversity of coaching disciplines. The following sections will summarise the challenges of existing coaching study and practice to explain why this SR was an essential step in the field of coaching.

\section{The role of psychology in contemporary coaching practice}

Summarising from some leading coaching studies (Grant, 2001; Berglas, 2002; Cavanagh, 2006; Naughton, 2002; Whybrow, 2008), psychological interventions are regarded bringing positive effects on coaching outcomes; however more rigorous evidence is required. The diversity of coaching disciplines (e.g. management, psychology, and education etc.) increases the difficulty in integrating existing evidence and identifying the best available knowledge for coaching practitioners to apply in their coaching sessions (Stober et al., 2006). In addition, it becomes a challenge to distinguish standardised assessment criteria for 
coaching professionalisation if the fundamental theoretical knowledge for professional coaching practice could not be confirmed through evidence-based research process.

Applying psychological principles in the coaching sessions are considered as one of the key elements for the enhancement of evidence-based practice (Grant, 2008). Here are the rationales to support this statement: firstly, psychology is a theoretically grounded science that underpins the processes and understanding of human change (Whybrow, 2008). The evidence-based coaching interventions (adopted from therapeutic models) fulfil the essential purpose of coaching, which is to facilitate a coachee's continuous learning and growth in the workplace through motivation and attitude change. For example, Simons \& Cleary (2006) suggested that a high degree of self-knowledge is essential for successful leadership; coaching practitioners should integrate elements of counselling to address the influences of the coachee's past and consequent attitudes, feelings and beliefs that underpin behaviour. Secondly, psychology is a recognised academic qualification, thus coaches who apply psychological grounded principles can ensure that a coaching process is based on enforceable ethical codes and supervised by relevant governing associations (e.g. British Psychological Society). Thirdly, having proper training in psychology assists the professional coach to minimise causing harm to a coachee with so far unrecognised mental health problems (Berglas, 2002; Cavanagh, 2006; Naughton, 2002). Though the general aim of coaching is to facilitate individual behavioural change and performance improvement in the workplace, studies indicated between $25 \%$ and $50 \%$ of individuals who attend life coaching programmes (mainly focus on personal development goals and aspirations of individuals) may have hidden mental health issues, such as stress, anxiety and depression (Green et al., 2005; Spence \& Grant, 2005). Therefore these studies indicated having a background in psychology or acquiring fundamental psychological knowledge is crucial to be able to identify if coachee 
has mental disorder issues and refer them to the appropriate therapeutic treatment such as counselling.

Several coaching reviews and book chapters (Bachkirova, 2008; Grant, 2001; Passmore \& Fillery-Travis, 2011; Whybrow, 2008) have addressed the role of psychological principles in coaching. These papers indicated it is necessary to build on this groundwork to conduct a more in depth review, with clear review criteria which assess the quality of any primary sources, to allow us to spell out clear hypotheses for further investigation.

\section{The role of coaching relationship for facilitating coaching outcomes}

As discussed earlier, it remains a challenge for coaching researchers to examine the most effective coaching method for a positive coaching outcome due to the diversity in domains, methods and outcomes discussed earlier. Therefore coaching research has shifted its focus from examining singular coaching interventions to investigating the active ingredients in a productive coaching process (Palmer \& McDowall, 2010). The choice of coaching interventions usually depends on the coachee's individual development obstacles and organisational context, and should be tailored in accordance with the coachee's individual scenario. This indicates that adopting one singular coaching framework is not sufficient for the potentially complex coaching context. Therefore a contextual-model (Stober et al., 2006) of coaching which integrates various techniques might be more helpful for productive coaching outcomes. This model is expanded from the components described by Wampold (2001) for a contextual model for psychotherapy. A Contextual Coaching Approach, which aims to understand the process of coaching, including "what the common themes" are that benefit to coaching process and outcomes. Seven thematic factors for the Contextual Coaching Approach, which outline the essential elements to facilitate effective coaching outcomes, were outlined to explain why coaching relationship plays a key role in 
contemporary coaching practice and study (Stober et al., 2006). These seven thematic factors highlight that coaching is a collaborative process in which the coach and coachee work toward mutual goals. Hence, an "effective" and "constructive" coaching relationship is the key factor for positive coaching outcomes as most of the coaching process relies on two people's (coach-coachee) conversation and interactions.

Inheriting the Contextual Coaching Approach, de Haan (2008) transferred a concept from a meta-analysis result in psychotherapy study (Wampold, 2001) to the field of coaching as both interventions share a very similar process: the essence of therapeutic and coaching process relies on sustaining interpersonal interactions between therapist/coach and patient/coachee. This meta-analysis indicated there was no significant difference in effectiveness on desired outcomes between different approaches and techniques. The working alliance (relationship) between the therapist and client was identified as the most effective ingredient for facilitating a positive therapy outcome across all approaches. Based on the aspect of 'outcome equivalence' in this study (Wampold, 2001), a quality coaching relationship across the coaching engagement was inferred as the most essential common factors for positive coaching outcomes. Indeed, the age of "relational coaching" has been confirmed by means of a number of quantitative studies. These studies examined a positive correlation between the coaching relationship and results, such as coachees' self-efficacy (Baron \& Morin, 2009; Boyce et al., 2010; de Haan et al., 2013).

In a short summary, the coaching relationship appears as an essential role in contemporary coaching study and practice based on the result of positive correlation with coaching outcomes (e.g. self-efficacy). However the questions about what the active factors are for an effective coaching relationship and how these factors could be optimised in the coaching process have not be answered. The next section will briefly discuss these issues based upon current literature. 


\section{What are active ingredients in an effective coaching relationship?}

As investigating active factors for an effective coaching relationship become the key focus in contemporary coaching study. de Haan (2008) conducted a survey study with 71 executive coaching clients to distinguish "helpful" elements in the coaching journey and how these elements could be "optimised" to create a constructive coaching process. The study results were similar to the meta-analysis in the field of psychotherapy (Wampold, 2001); an effective coaching relationship can be the key indicator for a positive outcome. In order to identify what the coach's role is in an effective coaching process; qualitative questions were included in de Haan's study (2008) to elicit effective attributes for a professional coach to generate a greater effect on coaching alliance. This study outlined three attributes of the coach, which were (a) listening, (b) understanding and (c) encouragement to facilitate coachee participants' learning and development in the coaching process. This study revealed that the coach plays a key role in initiating a harmonious relationship in the coaching journey, although the specific behavioural indicators were not identified here. Another quantitative study (de Haan et al., 2013) was carried out with 156 coach-coachee paired participants to examine the correlation between coaching relationship (Working Alliance) and outcomes (Self-efficacy). It investigated whether personality matching between coach and coachee is an influential factor in an effective coaching relationship. Though there was no strong correlation between personality matching and coaching relationship; subjective matching where the coach and client physically met each other and had an interview or trial session was recognised as the critical stage/moment to determine the effectiveness of the subsequent relationship on the coaching journey. This disclosed that the coach has the opportunity and responsibility to initiate a positive impression and relationship for the subsequent sessions. Hence, identifying and examining what attributes a professional coach should acquire to 
establish a constructive coaching relationship are critical steps in contemporary Coaching Psychology research.

\section{Analysis of existing professional coaching frameworks}

Summarising the previous discussion, there is a need to investigate explicit attributes for a coaching practitioner and how these link to any effects on the coaching relationship. This is a potential key step for the development of evidence-based coaching. Many governing professional associations worldwide such as the Association for Coaching (AC), The British Psychological Society (BPS), the European Mentoring and Coaching Council (EMCC) and the International Coach Federation (ICF) have developed professional frameworks in consultation with members to outline the benchmark required for those who would like to practice as a professional coach. However, certain aspects of these frameworks appear to require further validation and investigation. The defining elements presented on their published documents are summarised in Table 1. 


\section{Table 1}

Summary of Previous Coaching Competency Frameworks

\begin{tabular}{|c|c|c|c|c|c|c|}
\hline Association & Sources of Published Documents & $\begin{array}{l}\text { Investigation } \\
\text { Process }\end{array}$ & Structure & $\begin{array}{l}\text { Level of } \\
\text { rating }\end{array}$ & $\begin{array}{l}\text { Psychologica } \\
1 \text { perspective }\end{array}$ & $\begin{array}{l}\text { Emphasis } \\
\text { on } \\
\text { Coaching } \\
\text { Relationshi } \\
\text { p }\end{array}$ \\
\hline $\begin{array}{l}\text { BPS } \\
\text { Standard } \\
\text { Framework } \\
\text { for Coaching } \\
\text { Psychology } \\
(2008)\end{array}$ & $\begin{array}{l}\text { (BPS, 2007) } \\
\text { http://www.bps.org.uk/networks- } \\
\text { and-communities/member- } \\
\text { networks/special-group-coaching- } \\
\text { psychology }\end{array}$ & $\begin{array}{l}\text { Meta-analysis of } \\
\text { previous research } \\
\text { and coaching } \\
\text { expert's personal } \\
\text { experiences }\end{array}$ & $\begin{array}{l}4 \text { broad } \\
\text { clusters } \\
112 \\
\text { competencie } \\
\mathrm{s}\end{array}$ & $\begin{array}{l}\text { Not } \\
\text { specifically } \\
\text { refer to more } \\
\text { generic } \\
\text { coaching } \\
\text { competencie } \\
\text { s such as } \\
\text { listening, } \\
\text { building } \\
\text { rapport, } \\
\text { managing } \\
\text { the process. }\end{array}$ & Yes & Yes \\
\hline $\begin{array}{l}\text { ICF } \\
\text { Professional } \\
\text { Coaching } \\
\text { Core } \\
\text { Competencie } \\
\text { s (2009) }\end{array}$ & $\begin{array}{l}\text { (Griffiths \& Campbell, 2008) } \\
\text { http://www.coachfederation.org.uk/ }\end{array}$ & $\begin{array}{l}\text { Grounded Theory } \\
\text { Approach (five } \\
\text { coaches and nine } \\
\text { coaching clients) }\end{array}$ & $\begin{array}{l}4 \\
\text { competency } \\
\text { groups } \\
11 \\
\text { competencie } \\
\text { s } \\
70 \\
\text { behaviours }\end{array}$ & No & No & Yes \\
\hline $\begin{array}{l}\text { EMCC } \\
\text { Competency } \\
\text { Framework } \\
(2009)\end{array}$ & $\begin{array}{l}\text { (Wills, 2005) \& (Grant, Passmore, } \\
\text { Cavanagh, \& Parker, 2010) } \\
\text { http://www.emccouncil.org/ }\end{array}$ & $\begin{array}{l}\text { Developed through } \\
\text { an extensive } \\
\text { Europe-wide } \\
\text { consultative } \\
\text { process, drawing } \\
\text { on both expert and } \\
\text { practitioners' } \\
\text { experiences by } \\
\text { semi-structure } \\
\text { interviews or } \\
\text { questionnaires. }\end{array}$ & $\begin{array}{l}8 \\
\text { competency } \\
\text { groups }\end{array}$ & $\begin{array}{l}\text { Yes }(4 \\
\text { levels) } \\
\text { Foundation } \\
\text { Practitioner } \\
\text { Senior } \\
\text { Practitioner } \\
\text { Master } \\
\text { Practitioner }\end{array}$ & No & Yes \\
\hline $\begin{array}{l}\text { AC Coach } \\
\text { Accreditation } \\
\text { Scheme } \\
\text { Integrated } \\
\text { Coaching } \\
\text { Competency } \\
\text { Framework } \\
(2011)\end{array}$ & $\begin{array}{l}\text { http://www.associationforcoaching.co } \\
\mathrm{m}\end{array}$ & $\begin{array}{l}\text { Collected the } \\
\text { perspectives from } \\
\text { AC members in } \\
\text { early } 2005 \text {. } \\
\text { Five coaching } \\
\text { experts/practitioner } \\
\text { s (one is charted } \\
\text { psychologist) } \\
\text { helped to analyse } \\
\text { and combine the } \\
\text { data collected from } \\
\text { the members. }\end{array}$ & $\begin{array}{l}12 \\
\text { categories } \\
74 \\
\text { behaviours }\end{array}$ & No & No & Yes \\
\hline
\end{tabular}

\section{A number of similarities and differences between these frameworks were noted}

following an initial content analysis. First, all of these competency frameworks were

developed either by integrating previous evidence (meta-analysis) or consulting with their

internal coaching experts. Second, only the framework developed by EMCC sorted their 
competencies into groups to differentiate different job levels (e.g. foundation, practitioner, senior practitioner etc.). Third, most of these competency frameworks tended to consider coaching as a cross disciplinary developmental activity because no specific theoretical domain was highlighted in their documents. BPS Standard Framework for Coaching Psychologist is the only one coaching guideline which distinguished the role of psychology in coaching practice. In addition, the significance of coaching relationship has been emphasised in all competency frameworks, nevertheless behavioural indicators to facilitate an effective coaching relationship could not be identified in their documents. In a brief summary, existing competency frameworks appear more like a general guidance for people who would like to practice coaching. Because the purpose and focus of these frameworks were not addressed clearly in their documents and a relatively wide range of aspects was covered (e.g. contracting ethics, coaching process and relationship).

In a brief conclusion, coaching relationship has been highlighted and examined as the key indicator for a positive coaching outcome. In addition, the coach's role and behaviours have a significant influence on coaching relationship (de Haan, 2008). Though many coaching governing associations developed relevant frameworks for coaching practitioners to follow, they appear more like a general guideline and a relatively wide range of aspects were covered. Therefore, a comprehensive research study (including synthesising existing evidence systematically) to examine explicit attributes for the coaching practitioner to strengthen the coaching relationship built on previous psychologically based evidence (working alliance) is demanded. .

\section{A Systematic Review on Coaching Psychology}

A good literature review that informs us about current knowledge as well as gaps and research trends in the field therein is essential prior to any empirical study (Gough et al. 
2012); thus a systematic review which has been identified as the most rigorous approach for the enhancement of evidence-based practice (Briner, et al., 2009) was conducted. This review results (Lai \& McDowall, 2014) indicated (1) the role psychology plays in coaching has been strengthened in this review. A total of $69 \%$ included studies in this review investigated the associations between psychological interventions and coaching outcomes. In addition, the top five most frequently and examined psychological coaching interventions were outlined after synthesising relevant studies in this review. (2) This review enhanced the concept that coaching relationship is a key focus of coaching study and practice as one third of the included studies (44 of 141 papers) indicated coaching relationship the common factor for a positive coaching outcome. (3) This SR emphasised coaches' attributes have a significant impact on a constructive coaching relationship, five effective factors (such as building trust) and the initial coaching psychology KSAs (required knowledge, skills and attributes) were outlined to provide an overview which attributes a coaching practitioner should acquire to facilitate an effective coaching process. Therefore, this review concluded a primary study focusing on the effective attributes for coaching practitioners to establish and maintain a constructive coaching relationship is indeed required.

Therefore, following this SR results, a role analysis comprised three stage studies was carried out to identify and examine behavioural indicators for a professional coach to facilitate a better professional working relationship was carried out. The detailed research methods and results will be explained in the following sections. 


\section{Research Methods \& Findings}

\section{Study One: The development of Coaching Relationship Competency Framework}

The first study aimed to elicit effective coach's attributes/behavioural indicators to establish and maintain a constructive coaching relationship. This study inherited the review results from the SR on Coaching Psychology. According to the Standard Competency Modelling process (Shippmann, et al., 2000; Boyatzis, 2008), a variable combination and logically selected mix of multiple approaches was ranked as the top rigorous investigation method for competency modelling. Because one given method may only allow the researcher to collect limited data regardless of setting or target population. Therefore, a three-stage competency framework investigation process was formed: (a) Critical Incident Technique (CIT) (b) Thematic Analysis (TA) and; (c) Q-sorting. Also, it is essential for yielding a complete competency framework through involving multiple systematic samples of content experts to review and verify the effectiveness of identified competency framework. Table 2 summarises the research process of this study. 
Table 2. Overview of the Research Procedures

Stages Process and Outcomes

Stage One:

Critical Incident Interviews

25 interview transcripts.

Stage Two:

Thematic Analysis

Themes were extracted and coded from the

Data / theme extraction transcripts:

- 522 elements

- 341 initial attributes

- 278 behavioural descriptions

- $76.4 \%$ agreement level.

Data review

Language errors were amended and duplicate behaviours were integrated or discarded:

- 14 initial themes

- 103 behavioural indicators.

Stage Three: Q-sorting

\begin{tabular}{ll}
$1^{\text {st }}$ level Q-sorting & $\begin{array}{l}\text { Similar behaviours were clustered into the same } \\
\text { groups and competencies were named: }\end{array}$ \\
& -13 competencies \\
$2^{\text {nd }}$ level Q-sorting & -103 behavioural indicators. \\
Review of results & $\begin{array}{l}\text { Behaviours were re-clustered into the identified } 13 \\
\text { competency groups from previous step. }\end{array}$ \\
Totals: & Q-sorting results were reviewed and amended: \\
\hline
\end{tabular}

Critical Incident Technique

Critical Incident Technique (CIT), which was originally developed by Flanagan (1954), consists of a set of procedures for collecting direct observations of human behaviours in such a way as to facilitate their potential usefulness in solving practical problems and developing broad psychological principles (Flanagan, 1954). It outlines procedures for collecting observed incidents having special significance and meeting systematically defined criteria. CIT has been more frequently cited by industrial and organizational psychologists than any 
other article over the past 40 years (Anderson \& Wilson, 1997) but it has been also utilised across a diverse number of disciplines, including job analysis (Kanyangale \& MacLachlan, 1995; Stitt-Gohdes et al., 2000), counselling (Dix \& Savickas, 1995; McCormick, 1997) and performance appraisal (Evans, 1994; Schwab et al., 1975). This study used critical incident interviews with all participants to collect their perspectives on effective coaches' attributes drawn on the specific incidents or events relevant to their coaching experiences. This stage interviewed a total of 25 participants who had relevant coaching experiences playing different roles in the coaching process. In order to collect perspectives from a diversity of angles, four groups of participants were recruited: professional external coaches, coachees, organisational stakeholders (e.g. HR and coaching programmes evaluators) and internal coaches who attended coaching leadership and develop programmes in their organisation. Table 3 provides an overview of the value that each of these groups could offer. A one-on-one interview (either face-to-face, phone or email) was undertaken and each interview averaged 40 to 50 minutes. All participants were required to recall one recent positive coaching experience and share the effective elements optimising the coaching relationship. 
Table 3 Purpose of Each Interview Group

\begin{tabular}{ll}
\hline Interview Groups & Purpose of the Interview \\
\hline $\begin{array}{l}\text { External professional } \\
\text { caches with a psychological } \\
\text { background }\end{array}$ & $\begin{array}{l}\text { To probe effective coaching factors through } \\
\text { their "self-reflection" on specific coaching } \\
\text { experiences. }\end{array}$ \\
Coachees & $\begin{array}{l}\text { To probe effective coaching factors through their experiences of } \\
\text { specific coaching sessions to minimise the biased statements from } \\
\text { coaches' interview only. }\end{array}$ \\
$\begin{array}{l}\text { Organisational stakeholders } \\
\text { To investigate coaches' attributes through their } \\
\text { experiences in facilitating coaching sessions in } \\
\text { their respective organisations and their } \\
\text { expectations of coach selection because most of the coaching } \\
\text { programmes are commissioned by coachees' companies. }\end{array}$ \\
$\begin{array}{l}\text { Internal coaches who } \\
\text { attended a coaching training } \\
\text { programme in the } \\
\text { organisation }\end{array}$ \\
$\begin{array}{l}\text { To explore whether the coaching training they } \\
\text { attended met their needs and to probe effective } \\
\text { coaching factors through their "self-reflection" } \\
\text { on specific coaching experiences. }\end{array}$ \\
\hline
\end{tabular}

Thematic Analysis

Thematic Analysis (TA) method was used to extract effective attributes for a coaching psychologist from interview transcriptions in this study. TA is a method to be used with qualitative information (Boyatzis, 1998). It identifies analyses and reports patterns (themes) within qualitative data and translates them into quantitative information (i.e. codes). A pattern (theme) is usually found in the information that describes and organises the possible observations and interprets aspects of the phenomenon. The use of TA involves three distinct stages: a) deciding on sampling and designing issues; b) developing themes and a code; c) validating and using the code. TA is a flexible method which allows for a wide range of analytic options (Braun \& Clarke, 2008). It usually summarises the key features of a large body of data and offers a "rich description" of the data set. In addition, TA works very well in 
studies which seek to examine the perspectives of different groups within a topic/context (King, 2004).

All interviews were transcribed word-by-word for further data extraction and coding. Subsequently, thematic analysis was used to extract and code the themes from the interview transcriptions. This stage extracted 103 behavioural indicators for further analysis.

Q-sorting

Following the thematic analysis, two Q-sorting sessions were conducted with two coaching experts with psychological background and two post-graduate students in psychology. Q-methodology, developed in the 1930s, has been widely applied within psychology (Stephenson, 1953), although Q-methodology has been increasingly used in other disciplines, such as political science, particularly in the U.S.A. (Brown, 1980). Qmethodology is a technique incorporating the benefits of both qualitative and quantitative research. It involves Q-sorting, a method of data collection and factor analysis, to assess subjective (qualitative) information. In Q-methodology, participants are typically provided with a set of stimuli, usually statements, (known as the Q-sample) which they rank via a process, called Q-sorting (van Exel \& de Graaf, 2005). Participants are required to systematically force-sort a set of statements based on how strongly they agree or disagree with each statement (Jacobson \& Aaltio-Marjosola, 2001; Brewer et al., 2000). Usually several Q-sorting sessions are conducted in a study. The Q-sorting participates were asked to cluster the similar behavioural indicators into same group and name the competencies. A total of 13 competencies underpinned by 100 behavioural indicators were outlined in this study. Table 4 provides one example of these competencies: 
Table 4 One example of the draft Coaching Relationship Competency Framework $(\mathrm{CRCF})$

\begin{tabular}{|c|c|c|}
\hline Competencies & Definitions & Indicators \\
\hline $\begin{array}{l}\text { 1. Active } \\
\text { communicatio } \\
\text { n skills. }\end{array}$ & $\begin{array}{l}\text { Applying highly developed communication skills to } \\
\text { understand coachees' issues, enhance motivation, } \\
\text { facilitate change and build the rapport. Listening, } \\
\text { responding, questioning, asking challenging questions } \\
\text { and using body language appropriately. }\end{array}$ & e.g. Actively listening \\
\hline
\end{tabular}

In order to evaluate the consistency and accuracy of this draft competency framework, Coaching Relationship Competency Framework (CRCF), a cross validation questionnaire study was carried out afterwards which will be presented in the next section.

\section{Study Two: Establishing validation criteria: reliability and validity}

\section{Research Process}

Study two aimed to evaluate the reliability (such as internal consistency) validity of the draft CRCF by means of a questionnaire study. Two evaluations were used in this study. First, we transferred the draft CRCF into a behavioural-based questionnaire (Please see Table 4 for one example) comprising 100 items which are specific and clear behavioural descriptions (e.g. asking open questions) for respondents to rate to assess an effective coach's behaviours for facilitating a constructive cocaching relationship. Second, Coaching Alliance Inventory (CAI) which is modified from Tracey and Kokotovic's (Tracey \& Kokotovic, 1989) Working Alliance Inventory-Short Form was applied in this study to cross validate with CRCF questionnaire. According to Bordin (Bordin, 1979), the concept of "working alliance" is the combination of (a) a client and therapist agreement on goals (b) a client and therapist agreement on how to achieve the goals (c) the development of a personal bond 
between the participants. In 1986, Horvath and Greenberg (Horvath \& Greenberg, 1986) developed the Working Alliance Inventory (WAI) to specifically assess these three related dimensions which are rated by both coach and client. They stated the focus of WAI is a measure that captures both outcome variance and a clearly articulated relation with a specified body of theory. Hatcher and Barends (Hatcher \& Barends, 2006) put forward that the "working alliance" is used to refer to the quality and strength of the collaborative relationship between client and therapist; and O'Broin and Palmer (O'Broin \& Palmer, 2010) transferred this concept into a coaching relationship study. They highlighted that the psychological contract is very important in the coaching relationship because it provides a "container" for the joint purposive work of coaching to take place and also ensure the clarity and transparency in the process. This conceptualisation of the psychological contract through the coaching alliance framework emphasises the collaboration, mutual influence and cooperation of both coach and coachee, and goal-focus that is the nature of coaching in the coaching relationship. The working alliance provides a medium for collaboration and cocreation as well as a space for the coachee to feel safe and accepted enough to step into new forms of behaviour and creative action (Cavanagh, 2006). Therefore, the working alliance would appear to be an appropriate construct to evaluate the coaching relationship as its three core features (goal, task and bond) have been validated through a rigorous quantitative research (Tracey \& Koktovic, 1989).

Table 5 An Example of an Item Taken from the CRCF Questionnaire

\begin{tabular}{|c|c|c|c|c|c|c|}
\hline Statement & $\begin{array}{c}\text { Not } \\
\text { Demonstrated } \\
1\end{array}$ & $\begin{array}{c}\text { Not } \\
\text { Helpful } \\
2\end{array}$ & $\begin{array}{c}\text { Less } \\
\text { Helpful } \\
\mathbf{3}\end{array}$ & $\begin{array}{l}\text { Slightly } \\
\text { Helpful } \\
4\end{array}$ & $\begin{array}{c}\text { Helpful } \\
5\end{array}$ & $\begin{array}{c}\text { Very } \\
\text { Helpful } \\
6\end{array}$ \\
\hline $\begin{array}{l}\text { Asking challenging and } \\
\text { difficult questions to } \\
\text { facilitate the coachee to } \\
\text { think in a different way. }\end{array}$ & $\square$ & $\square$ & $\square$ & $\square$ & $\square$ & $\square$ \\
\hline
\end{tabular}


Prior to the official questionnaire launch, $\mathrm{CRCF}$ questionnaire and CAI were mapped to investigate their convergent and divergent validity and to determine whether they were theoretically related for a cross-validation examination. Both coaches and coachees were recruited to rate the $\mathrm{CRCF}$ and $\mathrm{CAI}$ based on their previous specific coaching experiences. The quality of coaching alliance/relationship is more likely to be assessed through subjective perspective, hence involving both key parties in the coaching process in this validation study tended to reduce the bias. A total of 107 respondents of this questionnaire study: 72 respondents were from coach groups and 35 were done by coachees.

Data Analysis

Initially, we evaluated the internal consistency of these 13 competencies, most (11 of 13 competencies) of the competencies' $\alpha$ valueswere larger than .7 ( $\alpha>.7)$. Though the $\alpha$ value of two competencies (e.g. "Using Resources") was slightly lower than .7, it may not suitable to determine whether these two competencies are unreliable before further analysis because the number of items also affects the value of $\alpha$ (Cortina, 1993). For example as the number of items on the scale reduces, $\alpha$ reduces. These two competencies had only two items each, thus further analysis (e.g. interclass correlation and cross-validation) was undertaken to determine which items should be retained in the final competency framework.

Second, we examined the relation between items of the CRCF and their corresponding CAI indicators. The stronger correlation between competencies and their corresponding CAI indicators, the greater effectiveness of this competency framework for establishing and maintaining a constructive coaching relationship. Almost half of the items (49 of 100 behavioural indicators) have a moderate correlation with their corresponding CAI indicators 
$(r \geq .3)$. In order to evaluate these items in a more rigorous way, the mean and range were also considered when screening the competencies and behavioural indicators.

According to standard competency framework modelling method (Shippmaan et al., 2000), differentiating different levels of competence articulates these behavioural indicators into a set of comprehensive framework. Also, it provides competency users a benchmark to distinguish high performers from others. Therefore, these behavioural items were sorted into groups/levels through examining their means, range and correlation with CAI. Three levels of competency were defined in this study; Table 6 outlines the criteria and features of each level:

Table 6 Three Levels for the CRCF

\begin{tabular}{|c|c|c|}
\hline Level & Definition & Criteria \\
\hline Soft Skills & $\begin{array}{l}\text { Items which showed both higher means and correlation } \\
\text { are defined as a "baseline" for any coaching sessions. } \\
\text { These behavioural indicators appear more like coach's } \\
\text { interpersonal skills. }\end{array}$ & $\begin{array}{l}\text { Means } \geq 5.3 \text { and } \\
\text { Correlation with } \mathrm{CAI} \geq \\
.30\end{array}$ \\
\hline Hard Skills & $\begin{array}{l}\text { Items which showed slightly lower means but significant } \\
\text { correlation with CAI. These indicators are more relevant } \\
\text { to coach's goal setting and process management skills. }\end{array}$ & $\begin{array}{l}\text { Means between } 3.0-5.3 \\
\text { Correlation with CAI } \\
\quad \geq .30\end{array}$ \\
\hline $\begin{array}{l}\text { Additional } \\
\text { Behavioural } \\
\text { Indicators }\end{array}$ & $\begin{array}{l}\text { Items which have minor influence on coaching } \\
\text { relationship but could be used to support Soft and Hard } \\
\text { Skills. }\end{array}$ & $\begin{array}{l}\text { Means } \geq .30 \\
\text { Correlation with CAI } \\
\quad<.30\end{array}$ \\
\hline
\end{tabular}

Soft Skills: (mean $\geq 5.3 ; \mathrm{r} . \geq .30)$. Items of which mean is equal to or larger than 5.3 and also the correlation coefficients with their corresponding CAI indicators are equal to or larger than .3 (r. $\geq .30)$ were defined as essential elements. These items had a stronger internal consistency and high correlation with CAI, thus they were considered as 'core behaviours' for an effective coaching relationship in this study. Seven items (e.g. listening actively) were identified as such Soft Interpersonal Skills". These behavioural indicators are more relevant to coaches' interpersonal skills to facilitate an effective coaching relationship 
Hard Skills: (mean between 3.0-5.3, r. $\geq .30$ ) Items of which are between 3.0 and 5.3; and also the correlation coefficients with their corresponding Coaching Alliance Inventory indicator are stronger than .30 were sorted into the second group. Items in this group have less strong internal consistency than Soft Skills. It does not indicate that these items are of minor importance; they facilitate the effective coaching relationship through a constructive way. A total of 38 items underpinning six competencies were sorted into this group. The majority of these items are more associated with goal setting and process management / contracting skills (e.g. developing realistic tasks and actions and inviting coaches to share what is important to them). Referring back the ultimate purpose of coaching, coaching aims to facilitate the coachee's behavioural and performance change through an interactive process between two people (coach and coachee). It implies that successful coaching is not only about building a harmonious relationship with the coachee but also assisting the coachee to achieve the goal.

Additional Behavioural Indicators: These items had relatively weak correlation with their correspondent CAI indicators; they still had moderate significant internal consistency $(\alpha$ $>$.30) which meant they still had a certain degree influence on supporting the Hard and Soft Skills to strengthen the coaching relationship and toward goal achievement.

In summary, a total of 75 behavioural indicators sorted into three groups/levels were retained in this competency framework for further examination by means of a quasiexperiment which will be presented in the next section. Table 7 shows the overview of CRCF. 
Table 7. Overview of CRCF

\begin{tabular}{|c|c|c|c|}
\hline Category & Description & $\begin{array}{c}\text { No. of } \\
\text { Competences }\end{array}$ & $\begin{array}{c}\text { No. of } \\
\text { Behavioural } \\
\text { Indicators }\end{array}$ \\
\hline Soft Skills & $\begin{array}{l}\text { Items which showed both higher } \\
\text { means and correlation are defined } \\
\text { as a "baseline" for any coaching } \\
\text { sessions. These behavioural } \\
\text { indicators appear more like coach's } \\
\text { interpersonal skills. }\end{array}$ & 2 & 7 \\
\hline Hard Skills & $\begin{array}{l}\text { Items which showed slightly lower } \\
\text { means but significant correlation } \\
\text { with CAI. These indicators are } \\
\text { more relevant to coach's goal } \\
\text { setting and process management } \\
\text { skills. }\end{array}$ & 6 & 38 \\
\hline $\begin{array}{l}\text { Additional Behavioural } \\
\text { Indicator }\end{array}$ & $\begin{array}{l}\text { Items which have minor influence } \\
\text { on coaching relationship but could } \\
\text { be used to support Soft and Hard } \\
\text { Skills. }\end{array}$ & & 30 \\
\hline Total & & & 75 \\
\hline
\end{tabular}

\section{Stage Three: The evaluation of the Coaching Relationship Competency Framework}

Study three was an extension of study two to examine the effectiveness of the CRCF. A quasi-experiment was carried out to compare a group that received training based on the identified competency framework with a control group that did not receive this training. A quasi-experimental study usually occurs in workplace field settings that participants cannot be placed into various treatment conditions for practical reasons, for example the study of the effects of training in the organisation. Yet the quasi-experiment study shares two features of true experiments: entailing the use of at least two treatment conditions and the measurement of intervening and dependent variables (Stone-Romero, 2002). However, one tracking diary report was combined in this study to diminish the potential threats to internal validity from quasi-experiment. The outcome measures were CRCF Questionnaire, Coaching Alliance 
Inventory (CAI) and Self-Efficacy Scale (SES). A total of 26 participants were recruited and assigned into groups (experimental or control group) and roles (coach or coachee) randomly. 
The research question and hypotheses of this study were as below:

"Does a coach training intervention designed around the CRCF facilitate a better coaching process and results than a control group intervention?"

Hypothesis 1: Coaches who attend a training workshop targeting the identified Coaching Psychology Competency Framework are able to facilitate a better coaching relationship as measured by the Coaching Alliance Inventory (rated by both coaches and coachees) created in the coaching session than those who have not attended this type of training. Hypothesis 2: Coaches who attend a training workshop targeting the identified Coaching Psychologist Competency Framework are able to demonstrate more effective coach behaviours as measured by the Coach Competency Evaluation (rated by both coaches and coachees).

Hypothesis 3: Coaches who attend a training workshop targeting the identified Coaching Psychologist Competency Framework will be more effective at facilitating the coachees to have a stronger confidence of self-belief level as measured by the Self-Efficacy Scale than those who have not attended this type of training.

Quantitative Data Analysis

Data analysis of this quasi-experiment was split into two major parts. The first part focused on the quantitative evaluations: Coaching Alliance Inventory (CAI), Coaching Psychologist Competency Framework Questionnaire (CRCF) and Self-Efficacy Scale (SES). It assessed the internal consistency of each measurement and compared two groups' (the group that attended the coaching training workshop, and the other group that only received a self-study training kit) results through conducting independent-sample t-tests. The second 
part integrated the respondents from open questions attached to the CRCF Questionnaire and diary tracking report by content analysis to investigate to what extent the CRCF-based training generated an effective coaching process.

\section{Coaching Alliance Inventory (CAI)}

The internal consistency of CAI evaluation in this study was assessed using Cronbach's alpha. The alpha value $(\alpha=.86)$ was accepted because it was higher than the general cut-off point $(\alpha=.7)$, It could be initially concluded that the coaching relationship of the group whose coaches had three-hours of training was preferable to the group that did not. Subsequently, an independent-samples t-test was conducted to compare items relating to the coaching relationship between the experimental and control groups. On average, the coaching alliance items for the experimental group had a higher mean than the control group. The significance was not very strong (all of the p values > .05), however medium-size effects (almost half of the item's $r>.30$ ) were observed. It could be initially concluded that the coaching relationship of the group whose coaches had three-hours of training was preferable to the group that did not.

\section{CRCF Questionnaire}

Coaches' behaviours in the coaching session were evaluated by the Coaching Psychologist Competency Framework questionnaire which was designed on the basis of the questionnaire study results. The internal consistency of this evaluation was very high $(\alpha=.90)$. Nearly all the item means of the experimental group (35 of 42items) were larger than the control group. This indicates coach participants who attended the training workshop demonstrated the competencies more effectively than participants who did not. The significance was not strong because only 13 of these 35 items' $\mathrm{p}$ values were smaller than .05 . 
However, $62 \%$ (26 items) of the items were between small and medium effect $(r \geq .10)$. Though, the difference between two groups was not significant, it does not determine this competency framework is invalid as (a) this was one "snapshot" training and evaluation due to time restriction (b) the control group had one week to self-learn behavioural indicators underpinning CRCF. Therefore, we could initially infer that the CRCF did facilitate coach participants to generate a more constructive coaching relationship in this study, but further evaluation is required to contrast the differences between two groups.

\section{Self-Efficacy Scale (SES)}

Coachees' goal achievement progress in this study was assessed by a generalised SelfEfficacy Scale (SES). Self-efficacy is defined as the belief that a person is capable of accomplishing a given task (Bandura, 1997).Self-efficacy has been widely applied in organisational studies, for instance organisational training and learning ((Bandura, 1997; Colquitt et al., 2000). It was also used as a key variable to predict the coaching outcomes in several coaching studies (Brouwers et al. 2006; Grant, 2008; Palmer \& Stewart, 2008; Baron $\&$ Morin, 2009). . The internal consistency of SES in this study was very high $(\alpha=.95)$. The t-test of the SES showed all of the item means of the experimental group were larger than the control group. However, half ( 4 of 8 ) of their $\mathrm{p}$ values was $>.05$ which indicated that the difference in self-efficacy belief between two groups was not significant. It indicated that coachee participants, facilitated by the coaches who attend the training workshop, had stronger confidence or faith in their behavioural changes or improvement in this study. In addition, a follow-up diary open-question questionnaire designed by the main researcher to draw out the participants' perspectives which were not covered by quantitative evaluations and gather more information reflecting on the coaching process they had in this study. 
Nevertheless, we could not confirm the significant difference between two groups due to insufficient sample size and one snap-shot evaluation.

In summary, these three quantitative evaluations indicated that coach participants from the experimental group (who attended the training workshop) facilitated a slightly better coaching relationship and generated more productive goal achievement progress (coachees' motivation and self-belief) through demonstrating a superior CRCF than the control group. Nevertheless, the data did not show strong significance. Thus, a longitudinal study design with larger participation size which might generate a more accurate study result should be carried out in the future research.

Qualitative Data Analysis

In order to investigate how and what the exact elements/behavioural indicators generated for a constructive coaching relationship are/ were, both coach and coachee participants were asked to respond to several open ended questions after the coaching session. For example, "What did the coach do /say to make you feel you have a "good relationship" with him/her?" Several competencies were emphasised by coach and coachee participants in establishing a constructive coaching relationship and generating positive results after integrating their responses to these open questions by means of a content analysis (e.g Active Communication Skills and Goal Focus/Goal Tracking). The viewpoints from both study groups) were aligned. Understanding the coachee's feelings and issues by applying highly developed communication skills and developing realistic plans through a collaborative process were the most effective ingredients for facilitating an effective coaching relationship.

Referring to the diary tracking report, the main challenge both groups faced was how they motivated themselves to commit to their development plans. For example, coachee participants had to manage their time effectively to fit in the development plans. In addition, 
being confident was also a key element in initiating the first step for behavioural changes. It took some coachee participants a certain time to adjust their mindset. The significant difference between the experimental and control group was the degree of their motivation. Coachees in the experimental group had stronger motivation and commitment to their plans. Coach participants who attended the training workshop generated more productive coaching attainment progress because they established a collaborative coaching relationship to enhance the coachees' self-motivation for change.

In a brief conclusion, the effectiveness of the CRCF was initially examined by means of a quasi-experimental study here; it did provide the coach with a professional guideline to enhance a better coaching relationship and outcomes (coachees' motivation and confidence level) in accordance with the study results. Nevertheless, there was no strong significance in the quantitative measurement as a bigger sample size and a longitudinal study design were required.

\section{Discussion}

$\mathrm{CRCF}$ is the first psychological grounded competency framework outlining explicit behavioural indicators for the enhancement of working alliance in coaching. This research investigated explicit competencies, as measured by behavioural indicators, which appear to be prerequisites for strengthening the working alliance and building an effective coaching relationship. The identified CRCF contributed the following three aspects:

1. The development of the CRCF filled a theoretical gap by identifying the explicit attributes to facilitate an effective coaching process from a Coaching Psychology perspective. As discussed earlier, subjective matching where the coach and coachee physically meet each other is a particularly critical stage for the subsequent effectiveness of the following relationship in the coaching journey (de 
Haan, 2008). To date, no published rigorous role analysis to yield definite coach's attributes for facilitating a constructive coaching relationship. This research addressed this by identifying 75 behavioural indicators sorted into three groups for different training purposes against Standard Competency Modelling criteria (Shippmann et al., 2000). Therefore, the development of the CRCF took existing coaching knowledge a step further towards yielding KSAs for an effective coaching alliance drawn on all the relevant coaching stakeholders' perspectives (coach, coachee and clientele) through a rigorous role analysis. This study outcome also aligned with contemporary therapeutic relationship study findings, which indicated the quality of shared understanding of the nature of the patient's problem (called therapeutic rapport) mainly counts on physicians' active communication abilities (Norfolk et al., 2009), a comprehensive skill-based training model provided professional guidelines for physicians to follow. In essence, what people actually do effectively and actively regarding communication and rapport, whether they are coaches or physicians, makes a difference to the quality of the relationship.

2. The CRCF built on previous psychologically based evidence to draw out effective behaviours for a constructive coaching relationship. The concept of a working alliance has been recognised as the focal point for integrating three major psychological traditions, psychoanalytic, humanistic psychology and psychotherapy, in a new paradigm (de Haan \& Sills, 2012). A meta-analysis in psychotherapy (Wampold, 2001) indicated there was no significant difference in effectiveness on desired outcomes between different and techniques. The working alliance, which emphasises relationship factors (such as mutual trust, empathy and respect) as well as links to positive outcome (clear mutual agreed goal and action 
plans), optimises the bond in the process of certain psychological helping interventions (e.g. counselling, therapy and coaching) and facilitates the joint purposive goal to be perfectively achieved (O’Broin \& Palmer, 2010). In other words, a preferable working relationship was recognised as the essential indicator toward desired outcomes in the counselling/therapy process. This "relationship" concept was transferred to coaching domain and examined by de Haan (2008): The coaching relationship is a key common factor for an effective coaching engagement. In addition, the association between the working alliance and coaching outcomes has been examined in research (Baron \& Morin, 2009; de Haan, et al., 2013). The content of the CRCF is consistent with the three key features of the working alliance: both interpersonal attributes (e.g. demonstrating empathy and emotional bond) and learning and facilitation skills (e.g. Goal Focus/Goal Tracking) are essential requirements for a coaching psychologist to establish a harmonious coaching process and facilitate a greater outcome. Therefore, in contrast with previous coaching relevant competency guidelines, the CRCF is the first framework that builds on psychologically proved evidence from psychoanalytic and humanistic perspectives and the transferring of theoretical concept from the working alliance into visible dimensions to be applied in a helping relationship.

In terms of methodical and practical contribution, $\mathrm{CRCF}$ is the first framework that has been developed and examined through a systematic and transparent process to meet the standard competency modelling criteria. In contrast with previous competency frameworks, the $\mathrm{CRCF}$ provides an explicit guideline (KSAs) to facilitate a greater coaching relationship, specifically focusing on coaching alliance. Competency items underpinning the CRCF tend 
to be brief and behavioural-based descriptions which are more user-friendly than previous frameworks. In addition, three differentiated groups of competencies provide a clearer guideline for coaching relevant training and development agenda. For instance, attributes under the first group which appear more likely interpersonal soft skills could be used as the baseline for fundamental coaching training as they had stronger correlations with their corresponding CAI indicators in this chapter. In summary, coaching training and development is in urgent need of standardisation because it has been widely applied in the organisational and workplace learning and development field but draws on varied disciplines. Therefore the CRCF, underpinned by explicit competencies and behavioural indicators, could feed the gaps of previous competency frameworks in coach training and development design.

\section{Conclusion}

The value of investment in coaching intervention will continue to be a major interest for practitioners and organisational stakeholders; however the most popular evaluation methods in the contemporary coaching industry rely on coachees' satisfaction and feedback rather than any concrete outcome measurements. This sort of subjective evaluation on coaching impacts cannot truly provide evidence for decision makers to justify whether the investment of coaching should be carried on in the organisations (Grant, 2007). As a researcher in Coaching Psychology, the positive impact on a coachee's work and life balance as well as learning and development is far more important than the ROI since the ultimate goal of coaching is to optimise people's potential and self-growth through systematic dialogue between the coach and coachee (Passmore \& Fillery-Travis, 2011). In order to yield valid and solid evidence, the development of evidence-based practice that investigates the best available knowledge or theoretical grounded interventions to apply in coaching practices has become the joint interest of researchers, practitioners and clients of coaching. 
This study aimed to strengthen the evidence-based coaching practice by developing and validating a CRCF through four studies. The effectiveness of the CRCF in training and development was investigated in a pilot field experiment and the results indicate relevance for practice. Future research could build on our findings for instance using longitudinal field studies, larger and also more professional samples and also conduct investigation into how skills identified through the CRCF work in conjunction with other coaching techniques. Last but not least, it still remains to be investigated which skills coaches bring to coaching process could be developed right at the start of a coaching relationship in order to maximise effective outcomes. This study contends that a behavioural approach, using clear and evidence-based models to guide interventions and best practice, will provide a basis for such future research. 


\section{References}

Anderson, L. and Wilson, S. (1997) 'Critical Incident Technique'. In Whetzel D.L. and Wheaton G.R. (Eds), Applied Measurement Methods in Industrial Psychology, pp. 89105. Palo Alto, CA: Davies-Black.

Bachkirova, T. (2008). Role of coaching psychology in defining boundaries between counselling and coaching. In Palmer S. and Whybrow A. (Eds.), Handbook of Coaching Psychology: a Guide for Practitioners. (2nd ed), pp. 351-366.

Bandura, A. (1977). Self-efficacy: toward a unifying theory of behavioral change. Psychological Review, 84(2), pp. 191.

Baron, L., \& Morin, L. (2009). The coach- coachee relationship in executive coaching: A field study. Human Resource Development Quarterly, 20(1), pp. 85-106.

Berglas, S. (2002). The very real dangers of executive coaching. Harvard Business Review, 80(6), pp. 86-93.

Bordin, E. S. (1979). The generalizability of the psychoanalytic concept of the working alliance. Psychotherapy: Theory, Research \& Practice, 16(3), pp. 252.

Boyatzis, R. E. (1998). Transforming qualitative information: Thematic analysis and code development. Sage.

Boyatzis, R. E. (2008). Competencies in the 21st century. Journal of Management Development, 27(1), pp.5-12.

Boyce, L., A Jackson, R Jeffrey Neal, \& J, L. (2010). Building successful leadership coaching relationships: examining impact of matching criteria in a leadership coaching program. Journal of Management Development, 29(10), pp. 914-931.

Braun, V. \& Clarke, V. (2008) Using thematic analysis in psychology. Qualitative Research in Psychology, 3(2), pp. 77-101. 
Brewer, G.A., Selden, S.C. and Facer, R.L. (2000), Individual conceptions of public service motivation, Public Administration Review, (Vol 60 No. 3), pp. 254-63.

Briner, R. B., Denyer, D., \& Rousseau, D. M. (2009). Evidence-based management: concept cleanup time? The Academy of Management Perspectives, 23(4), pp. 19-32.

Brouwers, A., Evers, W. J., \& Tomic, W. (2006). A quasi-experimental study on management coaching effectiveness. Consulting Psychology Journal: Practice and Research, 58(3), pp. 174.

Brown, S. (1980). Political Subjectivity: Applications of Q Methodology in Political Science. Yale. Yale University Press.

Cavanagh, M. (2006) Coaching from a systematic perspective: a complex adative conversation. In D.R. Stober and A.M. Grant (eds) Evidence Based Coaching Handbook: Putting Best Bractices to Work for Your Clients. Hoboken, NJ, John Wiley \& Sons.

Colquitt, J. A., LePine, J. A., \& Noe, R. A. (2000). Toward an integrative theory of training motivation: a meta-analytic path analysis of 20 years of research. Journal of Applied Psychology, 85(5), pp. 678.

Cortina, J. M. (1993). What is coefficient alpha? An examination of theory and applications. Journal of Applied Psychology, 78(1), pp. 98.

de Haan, E. (2008). Relational coaching: journeys towards mastering one-to-one learning. Chichester: John Wiley \& Sons.

de Haan, E., Duckworth, A., Birch, D., \& Jones, C. (2013). Executive coaching outcome research: The contribution of common factors such as relationship, personality match, and self-efficacy. Consulting Psychology Journal: Practice and Research, 65(1), pp. 40.

de Haan, E., \& Sills, C. (2012). Coaching relationships: relational coaching field book. 
Faringdon: Libri.

Dix, J.E. and Savickas, M.L. (1995). Establishing a Career: Developmental Tasks and Coping Responses. Journal of Vocational Behavior 47(1), pp. 93-107.

Flanagan, J. C. (1954) The critical incident technique. Psychology Bulletin, 51(4), pp. 327-58.

Grant, A. M. (2001). Toward a psychology of coaching: The impact of coaching on metacognition, mental health and goal attainment. Sydney: Coaching Psychology Unit, University of Sydney.

Grant, A. M. (2007). Past, present and future: the evolution of professional coaching and coaching psychology. In Palmer S. and Whybrow A. (Eds.), Handbook of coaching psychology: A guide for practitioners. pp. 23-39.

Grant, A. M. (2008). Past, present and future: the evolution of professional coaching and coaching psychology. In Palmer S. and Whybrow A. (Eds.), Handbook of Coaching Psychology: a guide for practitioners. (2nd ed), pp. 23-39.

Gough, D., Oliver, S., \& Thomas, J. (2012). An Introduction to Systematic Reviews. SAGE Publications.

Green, S., Oades, L. G., \& Grant, A. M. (2005). An evaluation of a life-coaching group program: Initial findings from a waitlist control study.

Hatcher, R. L., \& Barends, A. W. (2006). How a return to theory could help alliance research. Psychotherapy: Theory, Research, Practice, Training, 43(3), pp. 292.

Horvath, A., \& Greenberg, L. (1986). The Development of the Working Alliance Inventory. New York: Guilford Press.

Jacobson, S. and I. Aaltio-Marjosola (2001) Strong objectivity and the use of Q-methodology in cross-cultural research. Journal of Management Inquiry 10(3), pp. 228-248.

Kanyangale, M. and MacLachlan, M. (1995). Critical Incidents for Refugee Counsellors: An Investigation of Indigenous Human Resources. Counselling Psychology Quarterly 
8(1), pp. 89-101.

King, N. (2004). Using templates in the qualitative analysis of text. In C. Cassell and G.Symon (Eds.). Essential Guide to Qualitative Methods in Organizational Research. London: Sage.

Lai, Y. \& McDowall, A. (2014) A systematic review (SR) of coaching psychology: Focusing on the attributes of effective coaching psychologists. International Coaching Psychology Review 9(2), pp. 120-136.

McCormick, R. (1997). Healing Through Interdependence: The Role of Connecting in First Nations Healing Practices. Canadian Journal of Counselling 31(3). pp. 172-84.

Naughton, J. (2002). The coaching boom: Is it the long-awaited alternative to the medical model? Psychotherapy Networker, 42, July/August, pp. 1-10.

Norfolk, T., Birdi, K., \& Patterson, F. (2009). Developing therapeutic rapport: A training validation study. Quality in primary care, 17(2), pp. 99-106.

O'Broin, A., \& Palmer, S. (2010). Building on an interpersonal perspective on the coaching relationship. The Coaching Relationship: Putting People First, pp. 34.

Palmer, S., \& McDowall, A. (2010). The coaching relationship: putting people first. Routledge.

Passmore, J. \& Fillery-Travis, A. (2011). A critical review of executive coaching research: a decade of progress and what's to come. Coaching: An International Journal of Theory, Research and Practice, 4(2), pp. 70-88.

Shippmann, J. S., Ash, R. A., Batjtsta, M., Carr, L., Eyde, L. D., Hesketh, B., et al. (2000). The practice of competency modeling. personnel psychology, 53(3), pp. 703-740.

Simons, L., \& Cleary, B. (2006). The influence of service learning on students' personal and social development. College Teaching, 54(4), pp. 307-319.

Spence, G. B., \& Grant, A. M. (2005). Individual and group life-coaching: Initial findings 
from a randomised, controlled trial. Evidence-based coaching, 1, pp. 143-158.

Stephenson, W. (1953). The Study of Behaviour. Chicago: University of Chicago Press.

Stewart, L. J., Palmer, S., Wilkin, H., \& Kerrin, M. (2008). The influence of character: Does personality impact coaching success. International journal of evidence based coaching and mentoring, 6(1), pp. 32-42.

Stitt-Gohdes, W.L., Lambrecht, J.J. and Redmann, D.H. (2000). The critical-incident technique in job behavior research. Journal of Vocational Education Research, 25(1), pp. 59-84.

Stober, D., Wildflower, L., \& Drake, D. (2006). Evidence-based practice: A potential approach for effective coaching. International Journal of Evidence Based Coaching and Mentoring, 4(1), pp. 1-8.

Stone-Romero, E. F. (2002). The relative validity and usefulness of various empirical research designs. Handbook of research methods in industrial and organizational psychology, pp. 77-98.

Tracey, T. J. \& Kokotovic A. (1989). Factor structure of the Working Alliance Inventory. A Journal of Consulting and Clinical Psychology, 1(3), pp. 207-210.

van Exel NJA, de Graaf G. (2005). Q methodology: a sneak preview. [available from www.jobvanexel.nl]

Wampold, B. E. (2001). The Great Psychotherapy Debate: Models, Methods, and Findings. Willis, P. (2005). Competency Research Project: Phase 2 Output. London: European Mentoring and Coaching Council. Downloaded on 12 October, 2006, from:http://www.coachingpsychologist.net/Forums/showthread.php?t=47.

Whybrow, A. (2008). Coaching Psychology: Coming of Age? International Coaching Psychology Review, 3(3), pp. 219-240. 